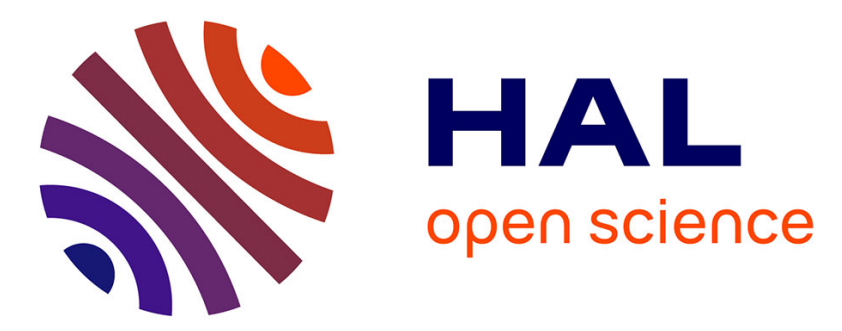

\title{
Wilms' tumor gene 1 (WT1) expression in subtypes of acute lymphoblastic leukemia (ALL) of adults and impact on clinical outcome
}

Antonia Busse, Nicola Gökbuget, Jan Michael Siehl, Dieter Hoelzer, Stefan Schwartz, Anika Rietz, Eckhard Thiel, Ulrich Keilholz

\section{To cite this version:}

Antonia Busse, Nicola Gökbuget, Jan Michael Siehl, Dieter Hoelzer, Stefan Schwartz, et al.. Wilms' tumor gene 1 (WT1) expression in subtypes of acute lymphoblastic leukemia (ALL) of adults and impact on clinical outcome. Annals of Hematology, 2009, 88 (12), pp.1199-1205. 10.1007/s00277-0090746-2 . hal-00535056

\section{HAL Id: hal-00535056 https://hal.science/hal-00535056}

Submitted on 11 Nov 2010

HAL is a multi-disciplinary open access archive for the deposit and dissemination of scientific research documents, whether they are published or not. The documents may come from teaching and research institutions in France or abroad, or from public or private research centers.
L'archive ouverte pluridisciplinaire HAL, est destinée au dépôt et à la diffusion de documents scientifiques de niveau recherche, publiés ou non, émanant des établissements d'enseignement et de recherche français ou étrangers, des laboratoires publics ou privés. 


\title{
Wilms' tumor gene 1 (WT1) expression in subtypes of acute lymphoblastic leukemia (ALL) of adults and impact on clinical outcome
}

\author{
Antonia Busse • Nicola Gökbuget • Jan Michael Siehl • \\ Dieter Hoelzer • Stefan Schwartz • Anika Rietz • \\ Eckhard Thiel • Ulrich Keilholz
}

Received: 8 February 2009/Accepted: 8 April 2009 / Published online: 29 April 2009

(C) Springer-Verlag 2009

\begin{abstract}
Wilms' tumor gene 1 (WT1) is gaining increasing attention as a therapeutic target molecule due to its common expression in acute leukemias and its involvement in cell proliferation. Here, we reported on WT1 messenger RNA expression levels at diagnosis in a series of 238 adult acute lymphoblastic leukemia (ALL) samples of various subtypes and clinical outcome. WT1 expression was found in 219 out of 238 ALL samples (92\%). Compared to a cohort of acute myeloid leukemia patients, the median WT1 expression level in ALL was significantly lower with large variations among different ALL subgroups. Specifically, WT1 expression levels were low in mature B-ALL and highest in ALL cases with co-expression of myeloid markers, making it a useful therapeutic target molecule in adult ALL with the exception of mature B-ALL. Cox regression analysis, considering ALL phenotype as well as molecular-cytogenetic subsets, revealed no independent prognostic role of WT1 expression level for disease-free and overall survival.
\end{abstract}

Keywords Adult ALL · WT1

A. Busse $(\bowtie) \cdot$ J. M. Siehl $\cdot$ S. Schwartz $\cdot$ A. Rietz $\cdot$ E. Thiel $\cdot$

U. Keilholz

Department of Medicine III, Charité, Campus Benjamin Franklin, Hindenburgdamm 30,

12200 Berlin, Germany

e-mail: antonia.busse@charite.de

N. Gökbuget $\cdot$ D. Hoelzer

Department of Medicine III, Johann Wolfgang Goethe University,

Frankfurt/M., Germany

\section{Introduction}

Wilms' tumor gene 1 (WT1) is an embryonic zinc-finger transcription factor, which was originally identified as a tumor suppressor gene inactivated in Wilms' tumors [1]. In addition, WT1 may function as a transcriptional cofactor and has also been implicated in post-transcriptional regulation, including RNA-splicing. As a result of alternative splicing, alternative translational initiation sites, and RNA editing, the WT1 gene can encode for as many as 36 different proteins [2]. The four major isoforms are characterized by the presence or the absence of exon 5 and/or the terminal 9 nucleotides of exon 9, which encodes the tripeptide KTS [3]. In normal tissue, WT1 is expressed during embryogenesis where it plays a pivotal role in the development of the urogenital tract $[4,5]$. In adults, it is expressed at very low levels in the kidney, ovary, testis, spleen, and normal hematopoietic progenitor cells $[1,6]$.

Overexpression of WT1 is present in a variety of malignant tumors with a putative role of an oncogene [7]. It plays an important role in the proliferation and inhibition of differentiation of neoplastic cells [8-10], making it a suitable therapeutic target, especially for tumor-directed immunotherapy [11-13].

Considering hematopoietic malignancies, high expression of WT1 was reported in blasts of acute myeloid leukemia (AML), chronic myeloid leukemia, and acute lymphatic leukemia (ALL) patients, and in myelodysplastic syndromes (MDS), both on RNA and protein levels [1417]. WT1 messenger RNA (mRNA) expression in leukemias was found to be several orders of magnitude higher in comparison to normal hematopoietic stem cell compartments [18], and several authors showed that WT1 expres- 
sion could be a useful marker for minimal residual disease, both in acute leukemias and MDS [19-21].

WT1 expression has extensively been studied in AML, but reports in adult ALL in relation to ALL subtypes and treatment outcome were limited. There are only few studies with small samples sizes showing WT1 overexpression in $65-100 \%$ of adult ALL cases [22-24].

In pediatric ALL, WT1 expression levels were higher in T- compared to B-lineage ALL. Interestingly, high WT1 levels in pediatric ALL were a negative prognostic factor for event-free and overall survival $[25,26]$.

Here, we examined WT1 mRNA expression levels in a large series of 238 samples from adult patients with ALL and the relation to ALL subtypes and clinical outcome.

\section{Materials and methods}

Patients

Between February 2003 and February 2005, bone marrow and peripheral blood samples from 238 adult patients with ALL and 43 patients with AML have been collected at diagnosis after informed consent. Approval by the appropriate ethics committee has been obtained, and analyses have therefore been performed in accordance with the ethical standards laid down in the 1964 Declaration of Helsinki.

ALL patients were treated within the German Multicenter ALL 07/03 study (http://ClinicalTrials.gov, identifier: NCT00198991) [27]. Characteristics of patients and samples were summarized in Table 1. Definition of risk groups are as follows: standard risk (SR) - B-progenitor ALL (complete remission (CR) at day 26 and white blood count (WBC) $<30,000 / \mu 1$, no pro-B-ALL/t $(4 ; 11) / A L L 1$ $A F 4$ positive ALL, no $\mathrm{t}(9 ; 22) / B C R-A B L$ positive ALL) and thymic ALL; high risk-B-progenitor ALL (CR at day 46 or $\mathrm{WBC}>30,000 / \mu 1$ or, pro-B-ALL/t( $4 ; 11) / A L L 1-A F 4$ positive ALL, no $\mathrm{t}(9 ; 22) / B C R-A B L$ positive ALL) and early T- or mature T-ALL; and very high risk (VHR) - $\mathrm{t}$ $(9 ; 22) / B C R-A B L$ positive ALL.

Characteristics of AML patients and samples were summarized in Table 2. Diagnoses were made according to morphologic and cytochemical criteria of the FrenchAmerican-British classification. Cytogenetic risk groups were defined as follows: high risk, $-5, \operatorname{del}(5 q),-7, \operatorname{inv}(3 q)$, $\mathrm{t}(3 ; 3), \mathrm{t}(6 ; 9), \mathrm{t}(6 ; 11), \mathrm{t}(11 ; 19)(\mathrm{q} 23 ; \mathrm{p} 13.1), \pm 8$ as single aberration or with additional aberration except $\mathrm{t}(9 ; 11)$, complex aberrations ( $\geq 3$ independent aberrations); low risk, $\mathrm{t}(8 ; 21)$, inv(16)/t(16;16), $\mathrm{t}(15 ; 17)$; and intermediate risk, all other karyotypic aberrations or a normal karyotype.
Table 1 Acute lymphoblastic leukemia: characteristics of patients and samples

\begin{tabular}{|c|c|}
\hline & Number $(\%)$ \\
\hline Total number of samples & $238(100)$ \\
\hline Origin: bone marrow/blood & $173(73) / 65(27)$ \\
\hline Female/male & $104(44) / 134(56)$ \\
\hline Age (median, range) & $43(17-80)$ \\
\hline \multicolumn{2}{|l|}{ Immunophenotype } \\
\hline Pro-B-ALL & $23(10)$ \\
\hline Common ALL & $102(43)$ \\
\hline Pre-B-ALL & $33(14)$ \\
\hline Mature B-ALL & $7(3)$ \\
\hline Early T-ALL & $26(11)$ \\
\hline Thymic T-ALL & $42(18)$ \\
\hline Mature T-ALL & $5(2)$ \\
\hline \multicolumn{2}{|l|}{ Molecular-cytogenetic subsets } \\
\hline $\begin{array}{l}\mathrm{t}(9 ; 22) / B C R-A B L \text { status available } \\
\text { (only c/pre-B-ALL) }\end{array}$ & $111(82)$ \\
\hline Positive/negative & $44(40) / 67(60)$ \\
\hline $\begin{array}{l}\mathrm{t}(4 ; 11) / A L L 1-A F 4 \text { status available } \\
\text { (only pro-B-ALL) }\end{array}$ & $23(100)$ \\
\hline Positive/negative & $13(57) / 10(43)$ \\
\hline \multicolumn{2}{|l|}{ Myeloid markers } \\
\hline Negative/positive (CD 13, 33, 15, or 65 ) & $167(70) / 71(30)$ \\
\hline CD13 & $29(12)$ \\
\hline CD33 & $14(6)$ \\
\hline CD13 and CD 33 & $14(6)$ \\
\hline CD 15 & $2(1)$ \\
\hline $\mathrm{CD} 65 \mathrm{~s}$ & $5(2)$ \\
\hline $\mathrm{CD} 15$ and $\mathrm{CD} 65 \mathrm{~s}$ & $7(3)$ \\
\hline Remission status available & 142 \\
\hline $\mathrm{CR}$ & $127(89)$ \\
\hline Risk group available & 146 \\
\hline $\mathrm{SR} / \mathrm{HR} / \mathrm{VHR}$ & $69(47) / 50(34) / 27(19)$ \\
\hline Median overall survival & 46.4 months \\
\hline Median disease-free survival & 18.2 months \\
\hline Median length of follow-up & 22 months \\
\hline
\end{tabular}

$S R$ standard risk, $H R$ high risk, $V H R$ very high risk, $C R$ complete remission

Blood and bone marrow samples, mRNA extraction, and reverse transcription

Fresh blood or bone marrow samples of ALL and AML patients were investigated. Because of low WT1 expression in normal B precursor cells in bone marrow, only samples containing at least $60 \%$ blasts were used for analysis. Blood and bone marrow samples were collected in heparinized tubes, and mononuclear cells were isolated by Ficoll 
Table 2 Acute myeloid leukemia: characteristics of patients and samples

\begin{tabular}{ll}
\hline & Number $(\%)$ \\
\hline Total number of samples & $43(100)$ \\
Origin: bone marrow/blood & $37(86) / 6(14)$ \\
Female/male & $26(60) / 17(40)$ \\
Age (median, range) & $60(21-82)$ \\
French-American-British type available & $36(84)$ \\
M0 & $1(3)$ \\
M1 & $7(19)$ \\
M2 & $6(17)$ \\
M3 & $2(6)$ \\
M4 & $11(30)$ \\
M5 & $8(22)$ \\
M6 & $0(0)$ \\
M7 & $1(3)$ \\
WBC $\left(\times 10^{9} / 1\right)$ available & $40(93)$ \\
$\leq 10 />10$ & $26(65) / 14(35)$ \\
Cytogenetic risk group available & $37(86)$ \\
Low/intermediate/high & $4(11) / 24(65) / 9(24)$ \\
\hline
\end{tabular}

Isopaque density gradient centrifugation (Pharmacia, Erlangen, Germany). Samples were resuspended in guanidium thiocyanate buffer and stored at $-80^{\circ} \mathrm{C}$. Further processing of samples was performed as previously described [28]. In brief, total RNA was isolated by RNeasy mini kit including RNase-free DNase set (Qiagen, Hilden, Germany) according to the manufactures recommendations. For reverse transcription, Omniscript reverse transcriptase kit (Qiagen, Hilden, Germany) was used.

\section{Quantification of WT1 expression levels}

Quantitative real-time reverse transcriptase-polymerase chain reaction (RT-PCR) assays were performed using a LightCycler (Roche Diagnostics) with specific primers for WT1 and the housekeeping gene porphobilinogen deaminase (PBGD) as described elsewhere [28]. For quantification, PCR products generated from WT1 complementary DNAs (cDNAs) and from PBGD cDNAs were cloned into the vector pCR2.1-TOPO (Invitrogen, Groningen, The Netherlands). A standard curve with three dilutions of the appropriate plasmid in duplicates was included in each PCR run. The specificity of the PCR products was confirmed by melting curve analysis as well as by gel electrophoresis.

Statistical analysis

Analysis of RT-PCR expression data was performed with the LightCycler software (version 3). Crossing points were assessed by the second derivate maximum algorithm and plotted against the concentrations of the standards. Sample concentrations were calculated using the plasmid standard curve resulting in marker concentrations. All samples were analyzed in duplicate. The average value of both duplicates was used as a quantitative value. To correct for differences of cDNA amount on a per-sample basis, results were provided as ratio to PBGD expression.

For comparison of WT1 expression levels among different ALL subtypes, significance was estimated by the Mann-Whitney $U$ test for comparison of two different groups or by the Kruskal-Wallis $H$ test for comparison of more than two groups.

Outcome events were CR to induction treatment, overall survival from the time of diagnosis to death or last followup, and disease-free survival to death, relapse, or last follow-up. Patients were grouped into four groups of WT1 expression levels based on distribution (quartiles). Survival curves were plotted according to the Kaplan-Meier method and were compared with the log-rank test. Cox regression was used to test for prognostic influence of WT1 expression level as a continuous variable. Tests were performed using SPSS 15.0 software.

\section{Results}

\section{Expression levels of WT1}

WT1 was detected in 219 of 238 (92\%) of ALL samples. Compared to a series of AML samples, WT1 expression levels largely overlapped, but the median expression level was lower in ALL than in AML [28] $\left(6.69 \times 10^{-3}\right.$ vs $1.19 \times$ $10^{-2}$ respectively, $p=0.024$, Fig. 1 a).

There were profound differences in WT1 expression levels among ALL immunophenotypic subgroups (Fig. 1b). In mature B-ALL, WT1 expression levels with a median of $3.37 \times 10^{-5}$ were below the normal bone marrow cutoff level [29] and significantly lower in comparison to the Tlineage and the more immature B-lineage subgroups $(p<$ 0.001, Fig. 1b). In ALL cases with co-expression of myeloid markers, WT1 expression levels were significantly higher than in samples without myeloid markers $(p<0.001$, Fig. 1c, d). Concerning $t(9 ; 22)$ translocation in the c/pre-BALL samples, no significant difference between $t(9 ; 22) /$ $B C R-A B L$ positive (median $2.38 \times 10^{-3}$ ) and negative samples (median $\left.7.49 \times 10^{-3}\right)$ was observed $(p=0.128$, Fig. 1e). Within the $\mathrm{t}(9 ; 22) / B C R-A B L$ positive group, a higher expression of WT1 was found in the c-ALL samples compared to the pre-B-ALL samples (median $5.04 \times 10^{-3}$ vs $1.95 \times 10^{-4}$, respectively, $p=0.005$ ). No differences could be observed between $\mathrm{t}(4 ; 11) / A L L 1-A F 4$ positive and negative cases in the pro-B-ALL group ( $p=0.41$, Fig. $1 \mathrm{f})$. 

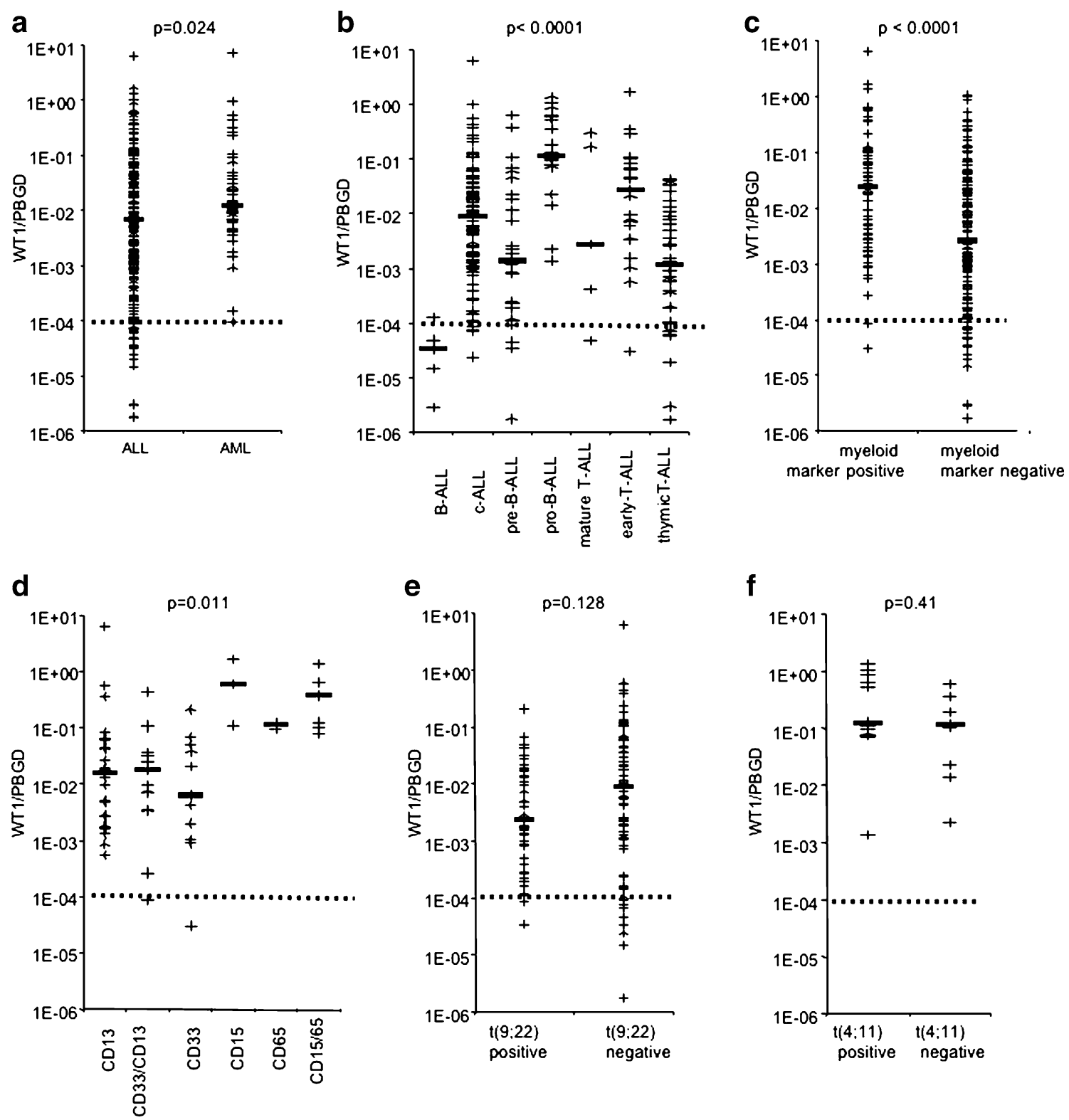

Fig. 1 WT1 expression levels in ALL (solid bar, median expression level; dotted line, healthy control bone marrow background level). a Comparison AML (median $1.19 \times 10^{-2}$ ) versus ALL (median $6.69 \times$ $\left.10^{-3}\right), p=0.024$. b Comparison among ALL immunophenotypes: BALL (median $3.37 \times 10^{-5}$ ), c-ALL (median $8.89 \times 10^{-3}$ ), pre-B-ALL (median $1.37 \times 10^{-3}$ ), pro-B-ALL (median $1.17 \times 10^{-1}$ ), T-ALL (median $2.79 \times 10^{-3}$ ), early T-ALL (median $2.69 \times 10^{-2}$ ), and thymic T-ALL (median $1.16 \times 10^{-3}$ ). c Comparison between myeloid marker positive (median $2.45 \times 10^{-2}$ ) vs negative cases (median $2.63 \times 10^{-3}$ ), $p<$

WT1 expression levels did not correlate with absolute leukocyte or blast count at diagnosis, involvement of lymph nodes, liver, spleen, or central nervous system (data not shown). Comparing ALL blasts in bone marrow and ALL blasts in blood considering different subtypes, we observed no differences in WT1 expression levels.
0.0001. d Comparison of co-expression of different myeloid markers: CD13 (median $1.56 \times 10^{-2}$ ), CD33 (median $\left.6.28 \times 10^{-3}\right), \mathrm{CD} 13+\mathrm{CD} 33$ (median $1.84 \times 10^{-2}$ ), CD15 (median 5.9 $\times 10^{-1}$ ), CD65 (median 1.16× $10^{-1}$ ), and CD15+CD65 (median $3.72 \times 10^{-1}$ ). e Comparison of $\mathrm{t}(9 ; 22) / B C R-A B L$ positive (median $2.38 \times 10^{-3}$ ) vs negative cases (median $\left.7.49 \times 10^{-3}, p=0.128\right)$. f Comparison of $\mathrm{t}(4 ; 11) / A L L 1-A F 4$ positive (median $1.25 \times 10^{-1}$ ) vs negative cases (median $1.14 \times 10^{-1}$ ) in the pro-B-ALL group

\section{WT1 expression and outcome}

Clinical outcome data were available for 148 patients. There was no selection of patients. According to the distribution pattern of WT1 expression levels, patients were divided into four groups (quartiles): high $(\geq 0.44)$, intermediate high $(\geq 0.006-0.44)$, intermediate low $(\geq 0.0003$ - 
0.006), and low (0-0.0003) WT1 expression. Cox regression analysis revealed that WT1 expression level at diagnosis had no prognostic influence on overall survival $(p=0.3)$ and disease-free survival $(p=0.3)$, as depicted by the survival curves comparing the four different groups by log-rank test (Fig. 2). Also, when the different immunophenotypes (pre-B-/c-ALL, pro-B-ALL, mature T-ALL, thymic T-ALL) were individually analyzed for exploratory purposes, no prognostic influence on overall survival and disease-free survival in any group was observed.

In addition, there was no prognostic influence of WT1 expression level in the $\mathrm{t}(9 ; 22) / B C R-A B L$ negative pre- $\mathrm{B} / \mathrm{c}-$ ALL group with leucocytes $<30,000 / \mu 1$, which was defined as SR, nor in the $\mathrm{t}(9 ; 22) / B C R-A B L$ positive samples. Regarding $\mathrm{t}(4 ; 11) / A L L 1-A F 4$, no prognostic influence of WT1 expression was found in $\mathrm{t}(4 ; 11) / A L L 1-A F 4$ positive or negative samples. Moreover, WT1 expression level at diagnosis had no influence on remission rate.

\section{Discussion}

In the study reported here, high WT1 expression was found in more than $90 \%$ of adult ALL cases, although the median expression was lower compared to a previously published series of AML patients [28] in accordance to other reports $[17,22,23,30,31]$. Therefore, WT1 might be considered as a therapeutic target in ALL as in AML and MDS. Clinical vaccination trials with WT1 peptides and protein in AML/MDS have been in fact recently initiated [11-13]. However, when considering future immunotherapeutic clinical trials, differences in WT1 expression levels among different ALL subtypes will be of relevance.

In adult and pediatric ALL, higher WT1 expression levels were found in T-ALL compared to B-ALL [17, 22, $25,26,30,32]$. In contrast to these previous studies, we did not find general differences between the adult T-ALL and
B-ALL samples. However, the subgroup of mature B-ALL was characterized by WT1 levels that did not differ from normal bone marrow background. This is in line with the findings of Omran et al. [24]. Noteworthy, it is of interest in comparison to non-Hodgkin's lymphomas, which also do not express high levels of WT1 [33]. The low WT1 expression in mature B-ALL makes a clinical response to vaccination strategies targeting WT1 unlikely.

There were further differences of interest in WT1 expression levels. ALL blasts with aberrant co-expression of myeloid markers were associated with a significantly higher WT1 expression level than blasts without coexpression of myeloid markers, which corresponds to the overall difference in WT1 expression level between AML and ALL samples.

Besides immunophenotypic subsets, molecularcytogenetic subsets are of clinical relevance. Therefore, we analyzed WT1 expression levels in $\mathrm{t}(9 ; 22) / B C R-A B L$ and $\mathrm{t}(4 ; 11) / A L L 1-A F 4$ subsets, which are associated with a dismal prognosis. No significant difference between $\mathrm{t}(9 ; 22) / B C R-A B L$ positive and negative samples in the $\mathrm{c} /$ pre-B-ALL group could be detected, although, the median was higher for the $\mathrm{t}(9 ; 22) / B C R-A B L$ negative cases. Moreover, comparing $\mathrm{t}(4 ; 11) / A L L 1-A F 4$ positive samples with negative samples of the pro-B-ALL group revealed no difference. This observation is in contrast to a previous study of Cilloni et al. reporting significantly higher WT1 levels in $\mathrm{t}(9 ; 22) / B C R-A B L$ and $\mathrm{t}(4 ; 11) / A L L 1-A F 4$ positive cases [22]. This discrepancy may be related to the limited sample size analyzed in the previous study $(n=18)$ and the different housekeeping genes used $(A B L$, in the case of $t(9 ; 22) \beta$-glucuronidase). Moreover, Cilloni et al. compared different cytogenetic subsets without consideration of immunophenotype. Therefore, the difference between $\mathrm{t}(4 ; 11) / A L L 1-A F 4$ positive and negative cases in their study might rather reflect higher WT1 expression level in the pro-B-ALL group compared to other immunophenotypes.
Fig. 2 Kaplan-Meier curves: patients were divided into four groups: high $(>0.44)$, intermediate high $(>0.006-0.44)$, intermediate low $(>0.0003-0.006)$, and low $(0-0.0003)$ WT1 expression. Survival curves were compared with the log-rank test: (a) overall survival, $n=148$, $p=0.533$; and (b) disease-free survival, $n=138$ (patients with death in induction therapy and treatment failure excluded), $p=0.811$
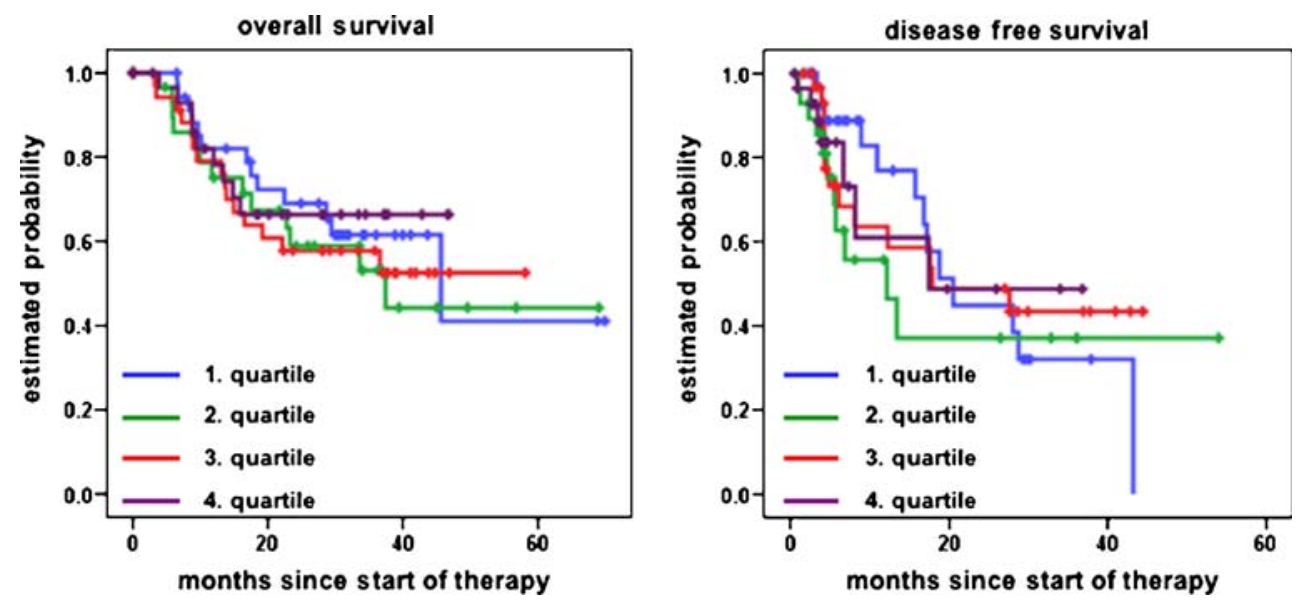
The prognostic significance of aberrant WT1 expression in AML and ALL is still a matter of debate [17, 30, 34-36]. In pediatric ALL, an abnormally high or low WT1 expression level was associated with a significantly increased risk of relapse [26].

In our cohort of 148 adult ALL patients, WT1 expression level was not associated with overall survival, disease-free survival, or remission rate, and not even in exploratory analyses within the different immunophenotypes or molecular-cytogenetic subsets. Taken together, the prognostic role of WT1 in ALL appears to be limited.

In conclusion, WT1 overexpression can be found in almost all cases of adult ALL with exception of the mature B-ALL. Therefore, as in AML, WT1 can be considered as a therapeutic target in the majority of adult patients with ALL. However, WT1 expression levels at diagnosis have no prognostic impact on the clinical outcome in adult ALL.

Acknowledgement We want to thank Alberto Fusi for critical reading the manuscript.

\section{References}

1. Haber DA, Housman DE (1992) Role of the WT1 gene in Wilms' tumour. Cancer Surv 12:105-117

2. Hohenstein P, Hastie ND (2006) The many facets of the Wilms' tumour gene, WT1. Hum Mol Genet 15(Spec No 2):R196-R201

3. Haber DA, Sohn RL, Buckler AJ et al (1991) Alternative splicing and genomic structure of the Wilms tumor gene WT1. Proc Natl Acad Sci USA 88(21):9618-9622. doi:10.1073/pnas.88.21.9618

4. Pritchard-Jones K (1999) The Wilms tumour gene, WT1, in normal and abnormal nephrogenesis. Pediatr Nephrol 13(7):620 625

5. Kreidberg JA (1996) Gene targeting in kidney development. Med Pediatr Oncol 27(5):445-452. doi:10.1002/(SICI)1096-911X (199611)27:5\&lt;445::AID-MPO10\&gt;3.0.CO;2-9

6. Maurer U, Brieger J, Weidmann E et al (1997) The Wilms' tumor gene is expressed in a subset of CD34+ progenitors and downregulated early in the course of differentiation in vitro. Exp Hematol 25(9):945-950

7. Sugiyama H (2001) Wilms' tumor gene WT1: its oncogenic function and clinical application. Int J Hematol 73(2):177-187. doi:10.1007/BF02981935

8. Algar EM, Khromykh T, Smith SI et al (1996) A WT1 antisense oligonucleotide inhibits proliferation and induces apoptosis in myeloid leukaemia cell lines. Oncogene 12(5):1005-1014

9. Inoue K, Tamaki H, Ogawa H et al (1998) Wilms' tumor gene (WT1) competes with differentiation-inducing signal in hematopoietic progenitor cells. Blood 91(8):2969-2976

10. Yamagami T, Sugiyama H, Inoue K et al (1996) Growth inhibition of human leukemic cells by WT1 (Wilms tumor gene) antisense oligodeoxynucleotides: implications for the involvement of WT1 in leukemogenesis. Blood 87(7):2878-2884

11. Xue S, Gao L, Gillmore R et al (2004) WT1-targeted immunotherapy of leukaemia. Blood Cells Mol Dis 33(3):288-290. doi:10.1016/j.bcmd.2004.08.018

12. Keilholz U, Menssen HD, Gaiger A et al (2005) Wilms' tumour gene 1 (WT1) in human neoplasia. Leukemia 19(8):1318-1323. doi:10.1038/sj.leu.2403817
13. Oka Y, Tsuboi A, Oji Y et al (2008) WT1 peptide vaccine for the treatment of cancer. Curr Opin Immunol 20(2):211-220. doi:10.1016/j.coi.2008.04.009

14. Cilloni D, Messa F, Carturan S et al (2004) Myelodysplastic syndromes. Ann N Y Acad Sci 1028:400-408. doi:10.1196/ annals. 1322.048

15. Menssen HD, Renkl HJ, Rodeck U et al (1995) Presence of Wilms' tumor gene (wt1) transcripts and the WT1 nuclear protein in the majority of human acute leukemias. Leukemia 9(6):1060 1067

16. Miwa H, Beran M, Saunders GF (1992) Expression of the Wilms' tumor gene (WT1) in human leukemias. Leukemia 6(5):405-409

17. Inoue K, Ogawa H, Sonoda $\mathrm{Y}$ et al (1997) Aberrant overexpression of the Wilms tumor gene (WT1) in human leukemia. Blood 89(4):1405-1412

18. Baird PN, Simmons PJ (1997) Expression of the Wilms' tumor gene (WT1) in normal hemopoiesis. Exp Hematol 25(4):312-320

19. Inoue $\mathrm{K}$, Ogawa H, Yamagami $\mathrm{T}$ et al (1996) Long-term followup of minimal residual disease in leukemia patients by monitoring WT1 (Wilms tumor gene) expression levels. Blood 88(6):22672278

20. Cilloni D, Saglio G (2004) WT1 as a universal marker for minimal residual disease detection and quantification in myeloid leukemias and in myelodysplastic syndrome. Acta Haematol 112 (1-2):79-84. doi:10.1159/000077562

21. Tamaki H, Mishima M, Kawakami M et al (2003) Monitoring minimal residual disease in leukemia using real-time quantitative polymerase chain reaction for Wilms tumor gene (WT1). Int J Hematol 78(4):349-356. doi:10.1007/BF02983561

22. Cilloni D, Gottardi E, De Micheli D et al (2002) Quantitative assessment of WT1 expression by real time quantitative PCR may be a useful tool for monitoring minimal residual disease in acute leukemia patients. Leukemia 16(10):2115-2121. doi:10.1038/sj. leu. 2402675

23. Inoue K, Sugiyama H, Ogawa H et al (1994) WT1 as a new prognostic factor and a new marker for the detection of minimal residual disease in acute leukemia. Blood 84(9):3071-3079

24. Omran HA, Shabani M, Vossough P et al (2008) Cross-sectional monitoring of Wilms' tumor gene 1 (WT1) expression in Iranian patients with acute lymphoblastic leukemia at diagnosis, relapse and remission. Leuk Lymphoma 49(2):281-290. doi:10.1080/ 10428190701784706

25. Im HJ, Kong G, Lee H (1999) Expression of Wilms tumor gene (WT1) in children with acute leukemia. Pediatr Hematol Oncol 16 (2):109-118. doi:10.1080/088800199277434

26. Boublikova L, Kalinova M, Ryan J et al (2006) Wilms' tumor gene 1 (WT1) expression in childhood acute lymphoblastic leukemia: a wide range of WT1 expression levels, its impact on prognosis and minimal residual disease monitoring. Leukemia 20 (2):254-263. doi:10.1038/sj.leu.2404047

27. Bruggemann M, Raff T, Flohr T et al (2006) Clinical significance of minimal residual disease quantification in adult patients with standard-risk acute lymphoblastic leukemia. Blood 107(3):11161123. doi:10.1182/blood-2005-07-2708

28. Siehl JM, Thiel E, Heufelder K et al (2003) Possible regulation of Wilms' tumour gene 1 (WT1) expression by the paired box genes PAX2 and PAX8 and by the haematopoietic transcription factor GATA-1 in human acute myeloid leukaemias. Br J Haematol 123 (2):235-242. doi:10.1046/j.1365-2141.2003.04622.x

29. Siehl JM, Reinwald M, Heufelder K et al (2004) Expression of Wilms' tumor gene 1 at different stages of acute myeloid leukemia and analysis of its major splice variants. Ann Hematol 83 (12):745-750. doi:10.1007/s00277-004-0941-0

30. Garg M, Moore H, Tobal K et al (2003) Prognostic significance of quantitative analysis of WT1 gene transcripts by competitive reverse transcription polymerase chain reaction in acute leukae- 
mia. Br J Haematol 123(1):49-59. doi:10.1046/j.1365-2141.2003. 04552.x

31. Menssen HD, Siehl JM, Thiel E (2002) Wilms tumor gene (WT1) expression as a panleukemic marker. Int J Hematol 76(2):103109. doi:10.1007/BF02982571

32. Chiusa L, Francia di Celle P, Campisi P et al (2006) Prognostic value of quantitative analysis of WT1 gene transcripts in adult acute lymphoblastic leukemia. Haematologica 91(2):270-271

33. Drakos E, Rassidakis GZ, Tsioli P et al (2005) Differential expression of WT1 gene product in non-Hodgkin lymphomas. Appl Immunohistochem Mol Morphol 13(2):132-137. doi:10.1097/01.pai.0000143786.62974.66
34. Barragan E, Cervera J, Bolufer P et al (2004) Prognostic implications of Wilms' tumor gene (WT1) expression in patients with de novo acute myeloid leukemia. Haematologica 89(8):926933

35. Bergmann L, Miething C, Maurer U et al (1997) High levels of Wilms' tumor gene (wt1) mRNA in acute myeloid leukemias are associated with a worse long-term outcome. Blood 90(3):1217-1225

36. Trka J, Kalinova M, Hrusak O et al (2002) Real-time quantitative PCR detection of WT1 gene expression in children with AML: prognostic significance, correlation with disease status and residual disease detection by flow cytometry. Leukemia 16 (7):1381-1389. doi:10.1038/sj.leu.2402512 